\title{
Autistic traits, systemising, empathising, and theory of mind in transgender and non-binary adults
}

Karson T. F. Kung ${ }^{1,2,3^{*}}$ (1)

\begin{abstract}
Background: Prior research examining autistic traits in gender minority adults has reported mixed findings. Most prior studies did not include non-binary individuals. Little is known about the mechanisms shaping autistic traits in gender minority adults. This study examined autistic traits, as well as constructs related to the extreme male brain theory of autism and the mindblindness theory, in transgender and non-binary adults.

Methods: An online survey was conducted to assess autism-related traits in 323 gender minority adults, including 74 transgender men (individuals assigned female at birth and identify as a man), 95 transgender women (individuals assigned male at birth and identify as a woman), 104 non-binary AFAB (individuals assigned female at birth and identify as non-binary), and 50 non-binary AMAB (individuals assigned male at birth and identify as non-binary). Autistic traits, systemising, empathising, and Theory of Mind (ToM) were measured using the Autism Spectrum Quotient (AQ), the short forms of the Systemising Quotient (SQ-Short) and the Empathy Quotient (EQ-Short), the 10-item version of the Empathy Quotient (EQ-10) and the Reading the Mind in the Eyes Test (Eyes Test). Participants'scores on these measures were compared with previously published scores based on large-scale general population samples including thousands of participants.
\end{abstract}

Results: On average, compared with control females in the general population samples, both transgender men and non-binary AFAB scored significantly higher on the AQ and the SQ-Short but scored significantly lower on the EQShort, the EQ-10, and the Eyes Test. No clear or consistent group differences emerged when transgender women and non-binary AMAB were compared with control males.

Limitations: The present study does not have a large sample of gender minority adults. It has been argued that the measures employed may not provide a precise assessment of the psychological constructs of interest. The present study has a "non-clinical" sample. However, not all gender minorities have access to or require clinical services, and so a "non-clinical" sample may be more representative of the gender minority community as a whole than samples recruited through clinics.

Conclusions: The current findings suggest a "masculinised" autism-related profile and reduced ToM in transgender men and in non-binary AFAB. These findings might be interpreted to support the extreme male brain theory of autism and the mindblindness theory. Further research is needed to corroborate these findings.

*Correspondence: karson.kung@hku.hk

1 Department of Psychology, University of Hong Kong, Pokfulam, Hong

Kong

Full list of author information is available at the end of the article

(c) The Author(s) 2020. This article is licensed under a Creative Commons Attribution 4.0 International License, which permits use, sharing, adaptation, distribution and reproduction in any medium or format, as long as you give appropriate credit to the original author(s) and the source, provide a link to the Creative Commons licence, and indicate if changes were made. The images or other third party material in this article are included in the article's Creative Commons licence, unless indicated otherwise in a credit line to the material. If material is not included in the article's Creative Commons licence and your intended use is not permitted by statutory regulation or exceeds the permitted use, you will need to obtain permission directly from the copyright holder. To view a copy of this licence, visit http://creativeco mmons.org/licenses/by/4.0/. The Creative Commons Public Domain Dedication waiver (http://creativecommons.org/publicdomain/ zero/1.0/) applies to the data made available in this article, unless otherwise stated in a credit line to the data. 
Keywords: Autism, Empathy, Extreme male brain, Gender minority, Non-binary, Systemising, Theory of mind, Transgender

\section{Background}

Gender minority is a term that can be used to describe individuals whose gender identity does not match their sex assigned at birth. Several studies have compared average group differences in autistic traits between gender minority adults and control adults. Jones et al. [1] conducted the first study on this topic and found elevated autistic traits in gender minority adults assigned female at birth compared with control females [1]. Similar findings have been reported in subsequent studies [2-5, but also see 6]. Regarding comparisons between gender minority adults assigned male at birth and control males, findings from these prior studies were mixed [1-6]. All these studies employed versions of the Autism Spectrum Quotient, a self-reported questionnaire, to assess autistic traits [1-6]. Prior studies recruited gender minority adults through clinics [1, 2, 4-6] and online platforms [3]. All prior studies included transgender men and transgender women [1-6], and two of the studies also included non-binary individuals [2, 3]. Only one study analysed data for non-binary individuals separately, although results were generally similar across the transgender and non-binary groups [3]. In addition to the studies examining autistic traits in gender minority adults, other lines of research have reported increased cross-gender identification, or gender variance, in autistic individuals $[7,8]$ and a higher prevalence of autism in individuals with gender dysphoria $[9,10]$. A recent large-scale study has reported higher rates of autism and other neurodevelopmental and psychiatric conditions in gender minority individuals [11] .

Little is known about the mechanisms underlying the elevation in autistic traits observed in gender minority adults assigned female at birth in prior research [1-5]. A popular theoretical framework used in prior research [1-6] is the extreme male brain theory of autism (EMB) [12], although the theory does not specifically focus on gender minorities. According to the EMB, autism can be considered as an extreme of a "male brain" characterised by increased systemising and decreased empathising [12]. A hypothesis related to the EMB proposes that heightened early androgen exposure contributes to the development of an 'extreme male brain' [13]. There is some empirical support for the links between early androgen exposure and systemising, empathising, and autistic traits, although findings have not been consistent across studies [14-22]. There is also evidence supporting an association between heightened early androgen exposure and reduced female-typical gender identity [23, 24]. Another relevant theoretical framework is the mindblindness theory, which proposes that in autism Theory of Mind (ToM), sometimes referred to as mind-reading, is impaired [25]. Although the mindblindness theory does not focus on gender differences or gender identity, males in the general population tend to score lower on certain measures of ToM than females [26, 27]. It has been proposed that heightened early androgen exposure may reduce ToM $[18,28]$. Therefore, it is possible that the elevated autistic traits in gender minority adults assigned female at birth are driven by increased systemising and reduced empathising and ToM.

There is limited research assessing the relevant theoretical constructs in gender minorities. Di Ceglie et al. [29] conducted the first study on systemising and empathising, using parent-reported questionnaires in a clinicbased sample of gender minority adolescents. This study found lower empathising and unaltered systemising in adolescent transgender boys compared with control females, whilst there were no differences in empathising or systemising between adolescent transgender girls and control males [29]. More recently, a study based on an online sample of transgender, non-binary, and control adults reported mixed findings regarding self-reported empathising and systemising, as well as ToM assessed by the Reading the Mind in the Eyes Test [3]. These mixed findings may be attributable to the small samples in the studies; there were 35 gender minority adolescents in total across two subgroups in the first study [29] and 109 gender minority adults in total across four subgroups in the second study [3].

The present study extends prior research by comparing gender minority adults' scores on measures of autistic traits, systemising, empathising, and ToM to previously published scores on the same measures from large-scale general population studies including thousands of participants. Based on prior research on autistic traits in gender minority adults [1-5], as well as the EMB and the mindblindness theory $[12,25]$, it was hypothesised that gender minority adults assigned female at birth would show increased autistic traits and systemising but reduced empathising and ToM compared with control females. Since prior findings regarding autistic traits in gender minority adults assigned male at birth were mixed, there were no specific hypotheses for comparisons between gender minority adults assigned male at birth and control males. 


\section{Methods}

\section{Participants}

In 2017, gender minority adults were recruited via numerous charities, organisations, and support groups specialising in sexual and gender minority issues in the UK and the US. These groups were approached via email and were asked to circulate an online survey invitation through their mailing lists and social media platforms. Participants completed the online survey on the Qualtrics platform. The survey was approximately 20 minutes long. In the survey, participants were asked to provide information about their "Sex Assigned At Birth" and "Gender Identity". For sex assigned at birth, they were given three options: "Male", "Female", and "Other". For gender identity, they were given four options: "Man", "Woman", "Nonbinary", and "Other". There were 323 gender minority adults, including 74 transgender men (individuals assigned female at birth and identify as a man; mean age $=32.88, \mathrm{SD}=14.59$ ), 95 transgender women (individuals assigned male at birth and identify as a woman; mean age $=42.14, \mathrm{SD}=17.02$ ), 104 non-binary $\mathrm{AFAB}$ (individuals assigned female at birth and identify as non-binary; mean age $=28.77, \mathrm{SD}=11.79$ ), and 50 nonbinary AMAB (individuals assigned male at birth and identify as non-binary; mean age $=42.92, \mathrm{SD}=14.34$ ). The overall sample (196 from the UK, 127 from the US) had a mean age of $35.83(\mathrm{SD}=15.69$; range $=18-76)$. Two participants choosing "Other" for the sex assigned at birth question and 10 cisgender participants were excluded from the current study, because the samples in these groups were too small for statistical analyses.

\section{Measures}

Autistic traits, systemising, and empathising were assessed by self-reported questionnaires including the Autism Spectrum Quotient (AQ; 50-item) [30] and the short forms of the Systemising Quotient (SQ-Short; 25-item) and the Empathy Quotient (EQ-Short; 22-item) [31]. A 10-item version of the EQ (EQ-10) [32] can also be derived using items from the EQ-Short. ToM was assessed using the revised version of the Reading the Mind in the Eyes Test (Eyes Test) [33], which consists of 36 grey-scale items/photos of people focusing on the area of the eyes. Participants were asked to identify the mental state of the person in each item/photo. Details of these measures, including their scoring methods and psychometric properties, can be found in the validation studies [30-33]. As indicated by Cronbach's $\alpha$, these measures had good internal consistency in the current study (AQ: $\alpha=0.87$; SQ-Short: $\alpha=0.87$; EQ-Short: $\alpha=0.93$; EQ-10: $\alpha=0.86$; Eyes Test: $\alpha=0.63$ ).

\section{General population samples as control groups}

The current sample's scores on these measures were compared with previously published scores on the same measures from general population samples of adults in large-scale studies. Descriptive statistics were extracted from the published studies for statistical comparisons. Descriptive statistics of the current sample and the general population samples are summarised in Table 1. For the AQ, control samples included 2562 females and 1344 males from Baron-Cohen et al. [34] and 298,084 females and 152,310 males from Ruzich et al. [35]. Other control comparisons were based on 1038 females and 723 males from Wakabayashi et al. [31] for the SQ-Short and the EQ-Short, 412,062 females and 259,544 males from Greenberg et al. [32] for the EQ-10, and 44,574 females and 43,482 males from Warrier et al. [36] for the Eyes Test. Participants in these general population studies were between 16 and 89 years of age.

\section{Analytical approach}

Comparisons between the current sample and the control groups were made according to the participants' sex assigned at birth (i.e., gender minority adults assigned female at birth were compared to control females and gender minority adults assigned male at birth were compared to control males). Within-sex analyses were conducted, because prior studies on this topic tend to focus on comparisons based on sex assigned at birth and because the relevant theoretical frameworks are generally based on genetic sex or sex assigned at birth rather than gender identity. Within each sex assigned at birth, transgender and non-binary individuals were separately compared to the control samples, because there is little research on non-binary individuals and separate analyses may usefully explore and detect potential group differences. One-sample $t$-tests were conducted to evaluate the statistical significance of the average group differences. All tests were two-tailed with alpha set at 0.05 . The Cohen's $d$ statistic was used as an effect size indicator to evaluate the magnitude of the average group differences (small effect: $d=0.2$; medium effect: $d=0.5$; large effect: $d=0.8$ ) [37].

\section{Results}

Transgender men and non-binary AFAB versus females in general population samples

The same results pattern was found in transgender men and in non-binary AFAB. Compared with control females in the general population samples, both transgender men and non-binary AFAB scored significantly higher on the AQ and the SQ-Short, but scored significantly lower on the EQ-Short, the EQ-10, and the Eyes Test. Details 
Table 1 Sample sizes, measures, and descriptive statistics for the current study and the general population studies

\begin{tabular}{|c|c|c|c|c|c|c|c|c|c|c|}
\hline & \multicolumn{2}{|l|}{$A Q$} & \multicolumn{2}{|c|}{ SQ-Short } & \multicolumn{2}{|c|}{ EQ-Short } & \multicolumn{2}{|l|}{ EQ-10 } & \multicolumn{2}{|c|}{ Eyes Test } \\
\hline & $n$ & Mean (SD) & $n$ & Mean (SD) & $n$ & Mean (SD) & $n$ & Mean (SD) & $n$ & Mean (SD) \\
\hline \multicolumn{11}{|l|}{ Current study } \\
\hline Transgender men & 72 & $22.98(9.02)$ & 72 & $20.83(9.45)$ & 72 & $20.11(10.90)$ & 72 & $8.38(5.21)$ & 74 & $26.57(4.80)$ \\
\hline Non-binary AFAB & 98 & $26.55(8.38)$ & 97 & $21.28(9.81)$ & 97 & $19.50(10.71)$ & 97 & $8.33(4.98)$ & 104 & $26.73(4.20)$ \\
\hline Transgender women & 90 & $20.37(7.76)$ & 89 & $23.64(10.01)$ & 89 & $23.96(9.54)$ & 89 & $10.50(4.80)$ & 95 & $26.25(3.58)$ \\
\hline Non-binary AMAB & 48 & $22.00(7.05)$ & 47 & $22.85(9.75)$ & 47 & $23.21(9.42)$ & 47 & $10.30(4.31)$ & 50 & $26.95(4.22)$ \\
\hline \multicolumn{11}{|l|}{ Baron-Cohen et al. [34] } \\
\hline Females & 2562 & $17.1(7.6)$ & & - & - & - & - & - & - & - \\
\hline Males & 1344 & $20.3(7.8)$ & - & - & - & - & - & - & - & - \\
\hline \multicolumn{11}{|l|}{ Ruzich et al. [35] } \\
\hline Females & 298,084 & $18.95(8.52)$ & - & - & - & - & - & - & - & - \\
\hline Males & 152,310 & $21.55(8.82)$ & - & - & - & - & - & - & - & - \\
\hline \multicolumn{11}{|l|}{ Wakabayashi et al. [31] } \\
\hline Females & - & - & 1038 & $15.4(8.77)$ & 1038 & $26.0(8.27)$ & - & - & - & - \\
\hline Males & - & - & 723 & $24.1(9.55)$ & 723 & $20.7(8.46)$ & - & - & - & - \\
\hline \multicolumn{11}{|l|}{ Greenberg et al. [32] } \\
\hline Females & - & - & - & - & - & - & 412,062 & $10.79(4.84)$ & - & - \\
\hline Males & - & - & - & - & - & - & 259,544 & $8.87(4.75)$ & - & - \\
\hline \multicolumn{11}{|l|}{ Warrier et al. [36] } \\
\hline Females & - & - & - & - & - & - & - & - & 44,574 & $27.85(3.55)$ \\
\hline Males & - & - & - & - & - & - & - & - & 43,482 & $27.08(3.75)$ \\
\hline
\end{tabular}

$\mathrm{AFAB}=$ individuals assigned female at birth; $\mathrm{AMAB}=$ individuals assigned male at birth. The variation in decimal places reported in the table reflects differing report styles across published studies

of inferential statistics and effect sizes are provided in Table 2.

\section{Transgender women and non-binary AMAB versus males in general population samples}

There were no significant differences in AQ scores between either transgender women or non-binary $A M A B$ and control males in the general population samples. Regarding SQ-Short scores, neither transgender women nor non-binary AMAB differed significantly from control males in the general population study. Compared with control males, transgender women scored significantly higher on the EQ-Short, the EQ-10, but scored significantly lower on the Eyes Test. Compared with control males, non-binary AMAB scored marginally significantly higher on the EQ-Short and significantly higher on the EQ-10, but did not differ significantly in terms of Eyes Test scores. Details of inferential statistics and effect sizes are provided in Table 2.

\section{Age and geographical location}

In the present study, there were no significant effects of age or geographical location on any of the measures in any of the subgroups or in the overall sample. Also, large-scale studies examining the effects of age and geographical location on the employed measures have reported negligible effects [32, 35, 36]. Hence, the current findings may not be attributable to any potential differences in age or location between the current and control samples.

\section{High-scoring individuals}

A cut-off score of $35+$ on the AQ has been used to categorise individuals as having the narrow autism phenotype $[1,38] .15 \%$ of transgender men, $19 \%$ of non-binary $\mathrm{AFAB}, 3 \%$ of transgender women, and $2 \%$ of non-binary $A M A B$ met the cut-off. Statistical comparisons cannot be made using the large-scale general population studies $[34,35]$, because those studies focused on average scores and did not examine the proportion of high-scoring individuals.

\section{"Brain types"}

Based on differences between standardised SQ-Short and EQ-Short scores, participants can be classed into one of five cognitive profiles, or "brain types". The relevant calculations and "brain type" classification in the current study were performed following the procedures outlined 
Table 2 Inferential statistics and effect sizes for the group comparisons

\begin{tabular}{|c|c|c|c|c|c|c|}
\hline Comparison & Measure and control study & Direction of Effect & $t$ & $p$ & Cohen's $d$ & $95 \% \mathrm{Cl}$ for $d$ \\
\hline \multirow{6}{*}{$\begin{array}{l}\text { Transgender men vs. } \\
\text { control females }\end{array}$} & AQ (vs. Baron-Cohen et al.) [34] & Transgender men > control females & 5.54 & $<0.001$ & 0.77 & {$[0.53,1.00]$} \\
\hline & AQ (vs. Ruzich et al.) [35] & Transgender men > control females & 3.80 & $<0.001$ & 0.47 & {$[0.24,0.70]$} \\
\hline & SQ-Short [31] & Transgender men > control females & 4.88 & $<0.001$ & 0.62 & {$[0.38,0.86]$} \\
\hline & EQ-Short [31] & Transgender men < control females & -4.58 & $<0.001$ & -0.70 & {$[-0.94,-0.46]$} \\
\hline & EQ-10 [32] & Transgender men $<$ control females & -3.93 & $<0.001$ & -0.50 & {$[-0.73,-0.25]$} \\
\hline & Eyes Test [36] & Transgender men < control females & -2.29 & 0.025 & -0.36 & {$[-0.59,-0.13]$} \\
\hline \multirow{6}{*}{$\begin{array}{l}\text { Non-binary AFAB vs. } \\
\text { control females }\end{array}$} & AQ (vs. Baron-Cohen et al.) [34] & Non-binary AFAB > control females & 11.16 & $<0.001$ & 1.24 & {$[1.03,1.44]$} \\
\hline & AQ (vs. Ruzich et al.) [35] & Non-binary AFAB > control females & 8.98 & $<0.001$ & 0.89 & {$[0.69,1.09]$} \\
\hline & SQ-Short [31] & Non-binary AFAB > control females & 5.90 & $<0.001$ & 0.66 & {$[0.45,0.87]$} \\
\hline & EQ-Short [31] & Non-binary AFAB < control females & -5.98 & $<0.001$ & -0.76 & {$[-0.97,-0.55]$} \\
\hline & EQ-10 [32] & Non-binary $A F A B<$ control females & -4.86 & $<0.001$ & -0.51 & {$[-0.71,-0.31]$} \\
\hline & Eyes Test [36] & Non-binary $A F A B<$ control females & -2.72 & 0.008 & -0.32 & {$[-0.51,-0.12]$} \\
\hline \multirow{6}{*}{$\begin{array}{l}\text { Transgender women vs. } \\
\text { control males }\end{array}$} & AQ (vs. Baron-Cohen et al.) [34] & Transgender women > control males & 0.84 & 0.993 & 0.01 & {$[-0.20,0.22]$} \\
\hline & AQ (vs. Ruzich et al.) [35] & Transgender women $<$ control males & -1.44 & 0.152 & -0.13 & {$[-0.34,0.07]$} \\
\hline & SQ-Short [31] & Transgender women $<$ control males & -0.43 & 0.666 & -0.05 & {$[-0.27,0.17]$} \\
\hline & EQ-Short [31] & Transgender women > control males & 3.22 & 0.002 & 0.38 & {$[0.16,0.60]$} \\
\hline & EQ-10 [32] & Transgender women > control males & 3.21 & 0.002 & 0.34 & {$[0.14,0.55]$} \\
\hline & Eyes Test [36] & Transgender women < control males & -2.27 & 0.026 & -0.22 & {$[-0.42,-0.02]$} \\
\hline \multirow{6}{*}{$\begin{array}{l}\text { Non-binary AMAB vs. } \\
\text { control males }\end{array}$} & AQ (vs. Baron-Cohen et al.) [34] & Non-binary AMAB > control males & 1.67 & 0.102 & 0.22 & {$[-0.07,0.51]$} \\
\hline & AQ (vs. Ruzich et al.) [35] & Non-binary $\mathrm{AMAB}>$ control males & 0.44 & 0.661 & 0.05 & {$[-0.23,0.33]$} \\
\hline & SQ-Short [31] & Non-binary $\mathrm{AMAB}<$ control males & -0.88 & 0.384 & -0.13 & {$[-0.43,0.16]$} \\
\hline & EQ-Short [31] & Non-binary $\mathrm{AMAB}>$ control males & 1.83 & 0.074 & 0.29 & {$[-0.00,0.59]$} \\
\hline & EQ-10 [32] & Non-binary $\mathrm{AMAB}>$ control males & 2.27 & 0.028 & 0.30 & {$[0.02,0.59]$} \\
\hline & Eyes Test [36] & Non-binary $\mathrm{AMAB}<$ control males & -0.21 & 0.832 & -0.03 & {$[-0.31,0.24]$} \\
\hline
\end{tabular}

$A F A B=$ individuals assigned female at birth; $A M A B=$ individuals assigned male at birth

Table 3 Descriptive statistics of "brain types" in the current sample and in Wakabayashi et al. [31]

\begin{tabular}{llllll}
\hline & Extreme Type E & Type E & Type B & Type S & Extreme Type S \\
\hline Transgender men & $6.9 \%(n=5)$ & $11.1 \%(n=8)$ & $43.1 \%(n=31)$ & $16.7 \%(n=12)$ & $22.2 \%(n=16)$ \\
Non-binary AFAB & $3.1 \%(n=3)$ & $7.2 \%(n=7)$ & $49.5 \%(n=48)$ & $16.5 \%(n=16)$ & $23.7 \%(n=23)$ \\
Control females [31] & $15.4 \%(n=160)$ & $25.9 \%(n=269)$ & $46.6 \%(n=484)$ & $8.5 \%(n=88)$ & $3.6 \%(n=37)$ \\
Transgender women & $4.5 \%(n=4)$ & $16.9 \%(n=15)$ & $41.6 \%(n=37)$ & $21.3 \%(n=19)$ & $15.7 \%(n=14)$ \\
Non-binary AMAB & $2.1 \%(n=1)$ & $10.6 \%(n=5)$ & $59.6 \%(n=28)$ & $17.0 \%(n=8)$ & $10.6 \%(n=5)$ \\
Control males [31] & $1.4 \%(n=10)$ & $5.8 \%(n=42)$ & $45.9 \%(n=332)$ & $24.1 \%(n=174)$ & $22.8 \%(n=165)$ \\
\hline
\end{tabular}

Extreme Type $E=$ Much stronger empathising relative to systemising; Type $E=$ Stronger empathising relative to systemising; Type $B=$ Balanced; similar levels of systemising and empathising; Type $S=$ Stronger systemising relative to empathising; Extreme Type $S=$ Much stronger systemising relative to empathising

in Wakabayashi et al. [31]. Descriptive statistics of "brain types" are summarised in Table 3. Approximately half of the cells in the current sample had a low value $(n<10)$, and thus no statistical tests were conducted to compare the distribution of "brain types" between subgroups in the current study and the general population sample [31]. However, descriptive statistics seem to indicate that, compared with control females, both transgender men and non-binary AFAB were more likely to have "brain types" of high systemising and low empathising. By contrast, it seems that the distribution of "brain types" was similar amongst transgender women, non-binary AMAB, and control males. 


\section{Supplementary analyses}

For completeness, correlations between the measures were examined. Potential group differences in mean scores on the measures between transgender men and non-binary $A F A B$ and between transgender women and non-binary $A M A B$ were also explored. These findings are reported in the Additional file 1.

\section{Discussion}

In the present study, all the comparisons between gender minority adults assigned female at birth and control females yielded significant results in the expected directions in line with the EMB [12] and the mindblindness theory [25]. Gender minority adults assigned female at birth scored higher on the AQ and the SQ-Short but lower on the EQ-Short, the EQ-10, and the Eyes Test. These current findings suggest that, on average, transgender men and non-binary AFAB show a "masculinised" autism-related profile and reduced ToM. The finding that autistic traits are elevated in transgender men and non-binary AFAB concurs with findings from most prior studies [1-5].

As for comparisons between gender minority adults assigned male at birth and control males, there were no differences in autistic trait and findings regarding the other measures were mixed. Due to a lack of an increase in autistic traits in transgender women or non-binary $A M A B$ in the present study, it is hard to interpret the relevant findings within the context of the EMB or the mindblindness theory. These theories are typically used to explain the development of autism or elevated autistic traits. It is unclear how one may apply these theories when a study population does not show elevated autistic traits. However, the current finding suggesting no difference in autistic traits between gender minority adults assigned male at birth and control males is consistent with findings from some prior studies $[1,2,6]$.

Heightened early androgen exposure may play a role in shaping the "masculinised" autism-related profile observed in gender minority adults assigned female at birth. Nonetheless, the behavioural effects of early androgen exposure on human gender development have been documented in both males and females [23, 24]. It is unclear why there was a sex-specific pattern in the present study; gender minorities assigned female at birth showed a more "masculine" autism-related profile, but gender minorities assigned male at birth did not show a more "feminine" autism-related profile. Noteworthy is that the hypotheses related to the EMB and the mindblindness theory were not developed to explain autistic traits in gender minorities. It would be useful for further research to extend the existing theoretical frameworks to formulate more specific theories that address autismrelated issues in gender minorities.

The present study suggests that some gender minority adults, especially those assigned female at birth, might have rigid thinking styles and might experience sociocognitive difficulties. Some gender minority adults may seek clinical and other professional services in different settings. Professionals working in various settings may need to attend to the relevant issues and adjust their communication styles when they provide support to gender minority adults.

\section{Limitations}

The AQ is not a diagnostic tool, and so high-scoring individuals may not necessarily receive a clinical diagnosis of autism. It has also been argued that the measures employed in the present study may not provide a precise assessment of the theoretical constructs of interest [39-41]. However, different versions of the employed measures are commonly used in studies testing the EMB and the mindblindness theory. There is also an increasing amount of research examining SQ and EQ scores in gender minority adults [11, 42]. Using these measures may enable comparisons across different study populations. In particular, a recent large-scale general population study found increased autistic traits and systemising but reduced empathising in gender minority individuals compared with cisgender individuals, although it was not possible for the study to make comparisons based on sex assigned at birth due to the way the sex/gender question was asked in the study [11].

The present study attempted to make comparisons to different control groups to see if the effects can be replicated across samples. There were two control samples for the AQ [34, 35] and the EQ measures [31, 32]. However, for the Eyes Test, there has only been one largescale general populations study [36]. The largest study measuring systemising and empathising employed the EQ-10 and the SQ-10 [32]. Whilst the EQ-10 can be derived using items on the EQ-Short, the SQ-10 cannot be derived using items on the SQ-Short. Hence, there was only one control sample for the SQ measure [31].

The present study relied on previously published descriptive statistics from various studies to make statistical comparisons, and thus it was difficult to adopt a conventional approach that would involve testing interactions before examining subgroup differences. However, interaction terms in statistical models may not detect meaningful or subtle patterns in studies without enormous subgroup samples. More importantly, there seems to be a clear pattern in the data 
suggesting a "masculinised" autism-related profile in gender minority adults assigned female at birth and generally unaltered scores on the relevant measures in gender minority adults assigned male at birth. In particular, for the comparisons between gender minority adults assigned female at birth and control females, all the effects concerning $\mathrm{AQ}, \mathrm{SQ}$, and $\mathrm{EQ}$ scores were moderate to large (Cohen's $d=0.47$ to 1.24 ) and highly significant (all $p$ values $<0.001$ ). Although the present study did not apply Bonferroni correction to individual $p$ values, these specific results would have remained significant after correction for multiple comparisons. The effects concerning ToM in gender minority adults assigned female at birth were smaller (Cohen's $d=0.32$ to 0.36$)$ and less significant ( $p=0.008$ to 0.025$)$. Like many other studies focusing on minority groups, the present study does not have a large sample. Further research is needed to corroborate the current findings, especially those on ToM. Further research may continue to investigate the mechanisms shaping autistic traits in both transgender and non-binary individuals.

The current sample was not recruited through a clinic. Nonetheless, not all gender minority adults have access to or require clinical services. Hence, compared with samples recruited through clinics, the current sample may be more representative of the gender minority community as a whole.

\section{Conclusions}

The current findings suggest that, on average, transgender men and non-binary AFAB show a "masculinised" autism-related profile and reduced ToM. These findings might be interpreted to support the EMB and the mindblindness theory. Further research is needed to corroborate the current findings.

\section{Supplementary information}

Supplementary information accompanies this paper at https://doi. org/10.1186/s13229-020-00378-7.

Additional file 1. Supplementary analyses.

\section{Abbreviations}

AFAB: Individuals assigned female at birth; AMAB: Individuals assigned male at birth; AQ: Autism Spectrum Quotient; EMB: Extreme male brain theory of autism; EQ-Short: Short version of the Empathy Quotient; EQ-10: 10-Item version of the Empathy Quotient; Eyes Test: Revised version of the Reading the Mind in the Eyes Test; SQ-Short: Short version of the Systemising Quotient; ToM: Theory of Mind.

\section{Acknowledgements}

The author would like to thank all the participants who made this research possible.

\section{Author's contributions}

KTFK designed the study, collected and analysed the data, wrote and approved the manuscript. The author read and approved the final manuscript.

Funding

Not applicable.

\section{Availability of data and materials}

The dataset generated and analysed during the current study is available from the corresponding author on reasonable request.

\section{Ethics approval and consent to participate}

Ethics approval was obtained from the Cambridge Psychology Research Ethics Committee, University of Cambridge.

\section{Informed consent}

Informed consent was obtained from all the participants.

\section{Consent for publication}

Not applicable.

\section{Competing interests}

The author declares no competing interests.

\section{Author details}

${ }^{1}$ Department of Psychology, University of Hong Kong, Pokfulam, Hong Kong. ${ }^{2}$ Gender Development Research Centre, Department of Psychology, University of Cambridge, Cambridge, UK. ${ }^{3}$ School of Psychology, University of Kent, Kent, UK.

Received: 22 May 2020 Accepted: 11 September 2020

Published online: 29 September 2020

\section{References}

1. Jones RM, Wheelwright S, Farrell K, Martin E, Green R, Di Ceglie D, et al. Brief report: female-to-male transsexual people and autistic traits. J Autism Dev Disord. 2012;42:301-6.

2. Nobili A, Glazebrook C, Bouman WP, Glidden D, Baron-Cohen S, Allison C, et al. Autistic traits in treatment-seeking transgender adults. J Autism Dev Disord. 2018:48:3984-94.

3. Stagg SD, Vincent J. Autistic traits in individuals self-defining as transgender or nonbinary. Eur Psychiatry. 2019;61:17-22.

4. Vermaat LE, van der Miesen Al, de Vries AL, Steensma TD, Popma A, Cohen-Kettenis PT, et al. Self-reported autism spectrum disorder symptoms among adults referred to a gender identity clinic. LGBT Health. 2018:5:226-33.

5. Heylens G, Aspeslagh L, Dierickx J, Baetens K, Van Hoorde B, De Cuypere $\mathrm{G}$, et al. The co-occurrence of gender dysphoria and autism spectrum disorder in adults: an analysis of cross-sectional and clinical chart data. $J$ Autism Dev Disord. 2018;48:2217-23.

6. Pasterski V, Gilligan L, Curtis R. Traits of autism spectrum disorders in adults with gender dysphoria. Arch Sex Behav. 2014;43:387-93.

7. van der Miesen Al, Hurley H, Bal AM, de Vries AL. Prevalence of the wish to be of the opposite gender in adolescents and adults with autism spectrum disorder. Arch Sex Behav. 2018:47:2307-17.

8. George R, Stokes MA. Gender identity and sexual orientation in autism spectrum disorder. Autism. 2018;22:970-82.

9. van der Miesen Al, Hurley H, De Vries AL. Gender dysphoria and autism spectrum disorder: a narrative review. Int Rev Psychiatry. 2016;28:70-80.

10. Thrower E, Bretherton I, Pang KC, Zajac JD, Cheung AS. Prevalence of autism spectrum disorder and attention-deficit hyperactivity disorder amongst individuals with gender dysphoria: a systematic review. J Autism Dev Disord. 2020;50:695-706

11. Warrier V, Greenberg DM, Weir E, Buckingham C, Smith P, Lai MC, et al. Elevated rates of autism, other neurodevelopmental and psychiatric diagnoses, and autistic traits in transgender and gender-diverse individuals. Nat Commun. 2020;7:11. 
12. Baron-Cohen S. The extreme male brain theory of autism. Trends Cogn Sci. 2002;6:248-54.

13. Baron-Cohen S, Knickmeyer RC, Belmonte MK. Sex differences in the brain: Implications for explaining autism. Science. 2005;310:819-23.

14. Auyeung B, Ahluwalia J, Thomson L, Taylor K, Hackett G, O'Donnell KJ, et al. Prenatal versus postnatal sex steroid hormone effects on autistic traits in children at 18 to 24 months of age. Mol Autism. 2012;3:17.

15. Auyeung B, Baron-Cohen S, Chapman E, Knickmeyer R, Taylor K, Hackett G. Foetal testosterone and autistic traits. Br J Psychol. 2009;100:1-22.

16. Auyeung B, Taylor K, Hackett G, Baron-Cohen S. Foetal testosterone and autistic traits in 18 to 24-month-old children. Mol Autism. 2010;1:11

17. Baron-Cohen S, Auyeung B, Nørgaard-Pedersen B, Hougaard DM, Abdallah MW, Melgaard L, et al. Elevated fetal steroidogenic activity in autism. Mol Psychiatry. 2015;20:369-76.

18. Chapman E, Baron-Cohen S, Auyeung B, Knickmeyer R, Taylor K, Hackett G. Fetal testosterone and empathy: evidence from the empathy quotient $(E Q)$ and the "reading the mind in the eyes" test. Soc Neurosci. 2006;1:135-48.

19. Auyeung B, Baron-Cohen S, Chapman E, Knickmeyer R, Taylor K, Hackett G. Foetal testosterone and the child systemizing quotient. Eur J Endocrinol. 2006;155:123-30

20. Whitehouse AJ, Mattes E, Maybery MT, Dissanayake C, Sawyer M, Jones $\mathrm{RM}$, et al. Perinatal testosterone exposure and autistic-like traits in the general population: a longitudinal pregnancy-cohort study. J Neurodev Disord. 2012:4:25.

21. Kung KTF, Spencer D, Pasterski V, Neufeld S, Glover V, O'Connor TG, et al. No relationship between prenatal androgen exposure and autistic traits: Convergent evidence from studies of children with congenital adrenal hyperplasia and of amniotic testosterone concentrations in typicallydeveloping children. J Child Psychol Psychiatry. 2016;57:1455-62.

22. Kung KTF, Constantinescu M, Browne WV, Noorderhaven RM, Hines M. No relationship between early postnatal testosterone and autistic traits in 18 to 30-month-old children. Mol Autism. 2016;7:15.

23. Hines M, Spencer D, Kung KT, Browne WV, Constantinescu M, Noorderhaven RM. The early postnatal period, mini-puberty, provides a window on the role of testosterone in human neurobehavioural development. Curr Opin Neurobiol. 2016;38:69-73.

24. Hines M. Neuroscience and sex/gender: looking back and forward. J Neurosci. 2020;40:37-433.

25. Baron-Cohen S. Mindblindness: an essay on autism and theory of mind. Boston: MIT Press/Bradford Books; 1995.

26. Devine RT, Hughes C. Silent films and strange stories: theory of mind, gender, and social experiences in middle childhood. Child Dev. 2013;84:989-1003.

27. Kirkland RA, Peterson E, Baker CA, Miller S, Pulos S. Meta-analysis reveals adult female superiority in "Reading the Mind in the Eyes Test". N Am J Psychol. 2013;15:121-46.

28. Khorashad BS, Khazai B, Roshan GM, Hiradfar M, Afkhamizadeh M, van de Grift TC. Prenatal testosterone and theory of mind development: findings from disorders of sex development. Psychoneuroendocrinology. 2018;89:250-5.
29. Di Ceglie D, Skagerberg E, Baron-Cohen S, Auyeung B. Empathising and systemising in adolescents with gender dysphoria. Opticon. 1826:2014:16

30. Baron-Cohen S, Wheelwright S, Skinner R, Martin J, Clubley E. The autism-spectrum quotient (AQ): evidence from asperger syndrome/highfunctioning autism, males and females, scientists and mathematicians. J Autism Dev Disord. 2001:31:5-17.

31. Wakabayashi A, Baron-Cohen S, Wheelwright S, Goldenfeld N, Delaney $J$, Fine D, et al. Development of short forms of the Empathy Quotient (EQ-Short) and the Systemizing Quotient (SQ-Short). Pers Individ Differ. 2006;41:929-40.

32. Greenberg DM, Warrier V, Allison C, Baron-Cohen S. Testing the empathizing-systemizing theory of sex differences and the extreme male brain theory of autism in half a million people. Proc Natl Acad Sci. 2018;115:12152-7.

33. Baron-Cohen S, Wheelwright S, Hill J, Raste Y, Plumb I. The, "Reading the Mind in the Eyes"Test revised version: a study with normal adults, and adults with Asperger syndrome or high-functioning autism. J Child Psychol Psychiatry. 2001;42:241-51.

34. Baron-Cohen S, Cassidy S, Auyeung B, Allison C, Achoukhi M, Robertson $\mathrm{S}$, et al. Attenuation of typical sex differences in 800 adults with autism vs. 3,900 controls. PLoS ONE. 2014;9:7.

35. Ruzich E, Allison C, Chakrabarti B, Smith P, Musto H, Ring H, et al. Sex and STEM occupation predict autism-spectrum quotient (AQ) scores in half a million people. PLoS ONE. 2015;10:10

36. Warrier V, Grasby KL, Uzefovsky F, Toro R, Smith P, Chakrabarti B, et al. Genome-wide meta-analysis of cognitive empathy: heritability, and correlates with sex, neuropsychiatric conditions and cognition. Mol Psychiatry. 2018;23:1402-9.

37. Cohen J. Statistical power analysis for the behavioral sciences. 2nd ed. Hillsdale: Erlbaum; 1988.

38. Wheelwright S, Auyeung B, Allison C, Baron-Cohen S. Defining the broader, medium and narrow autism phenotype among parents using the Autism Spectrum Quotient (AQ). Mol Autism. 2010;1:10.

39. Perrykkad K, Hohwy J. When big data aren't the answer. Proc Natl Acad Sci. 2019;116:13738-9.

40. Oakley BF, Brewer R, Bird G, Catmur C. Theory of mind is not theory of emotion: a cautionary note on the Reading the Mind in the Eyes Test. J Abnorm Psychol. 2016;125:818.

41. Ridley R. Some difficulties behind the concept of the 'Extreme male brain' in autism research. A theoretical review. Res Autism Spectr Disord. 2019:57:19-27.

42. Hendriks O, Wei Y, Warrier V, Richards G. Autistic traits, empathizing-systemizing, and gender variance. PsyArXiv. 2020. https://doi.org/10.31234/ osf.io/pavdx.

\section{Publisher's Note}

Springer Nature remains neutral with regard to jurisdictional claims in published maps and institutional affiliations.
Ready to submit your research? Choose BMC and benefit from:

- fast, convenient online submission

- thorough peer review by experienced researchers in your field

- rapid publication on acceptance

- support for research data, including large and complex data types

- gold Open Access which fosters wider collaboration and increased citations

- maximum visibility for your research: over $100 \mathrm{M}$ website views per year

At BMC, research is always in progress.

Learn more biomedcentral.com/submissions 